\title{
Estimation of unpredictable hospital demand variations in two Piraeus public hospitals, Greece
}

\author{
Zoe Boutsioli \\ Health Research Unit, Athens Institute for Education and Research, Athens, Greece \\ Correspondence: Zoe Boutsioli, MSc, PhD in Social Policy, Deputy Head. Address: Health Research Unit, Athens Institute \\ for Education and Research (ATINER), 20 Omirou Street, 10672 Kolonaki, Athens, Greece. E-mail: zb5@atiner.gr
}

Received: April 24, 2013

Accepted: June 5, 2013

Online Published: August 7, 2013

DOI : $10.5430 /$ jha.v2n4p126

URL: http://dx.doi.org/10.5430/jha.v2n4p126

\section{Abstract}

The scope of this paper is to estimate the unpredictable hospital demand variations in two public general hospitals in Piraeus, Greece. We used daily emergency admissions data between 1/1/2001 to 31/12/2005. To measure unpredictable hospital demand we used both a univariate Autoregressive Moving Average model and a multivariate time series model. In the latter one, four explanatory variables are tested: the weekend effect, the duty effect, the summer holiday effect, and the official holiday effect. The variance of forecasted residuals of each hospital regression for every day provides the estimated unpredictable demand.

The study verifies that daily emergency admissions are characterized by seasonal and weekly variations. In Tzaneio hospital, the unexpected part of emergency admissions increases over the five-year period, while in Nikaias hospital, it reduces. From the univariate analysis, it was found that the unpredictable part of admissions is not the same for the two hospitals and it also varies over the years. The variations of unpredictable hospital demand have increased by about $45 \%$ in Tzaneio hospital and have decreased by about $10 \%$ in Nikaias hospital. The results from the multivariate analysis show that the variations in unpredictable daily demand in Tzaneio hospital have less than doubled. On the contrary, the variations in unpredictable daily demand in Nikaias hospital have decreased by $20 \%$.

Due to these trends, a general conclusion is that at the beginning of the time period under investigation there are large variations in unpredictable demand between the two hospitals, which become smaller as we move on to 2005 .

\section{Key words}

Unpredictable demand, Hospital, Variation, Weekend effect, Greece

\section{I ntroduction}

Demand for hospital care is affected by many factors, such as travel distance ${ }^{[1]}$, meteorological factors ${ }^{[2]}$, adverse drug reactions ${ }^{[3]}$, supplier-induced demand ${ }^{[4]}$, hospital financing systems ${ }^{[5]}$, development of primary health care ${ }^{[6]}$ and a lot of others. However, total hospital demand could be separated into this that can be predicted and this that cannot be predicted (unpredictable). Over the last decades, researchers have attempted to estimate separately the factors that affect the unpredictable hospital demand mainly for bed standby capacity and its impacts on hospital $\operatorname{costs}^{[7-17]}$. 
The majority of empirical researchers use hospital admissions index to measure the unpredictable demand, and particularly, the category of emergency hospital admissions ${ }^{[12,17,18]}$. They applied a univariate method to measure unpredictable demand either in the UK or the Greek hospital sector. Hughes and McGuire ${ }^{[12]}$ employed monthly emergency admissions data to estimate the demand-forecasted equation. They defined the level of uncertainty faced by a hospital as the difference between realised and forecasted emergency demand. Similarly, Boutsioli ${ }^{[18]}$ based on the same method used more disaggregated data - daily data - to estimate the unpredictable hospital demand.

However, apart from univariate models to estimate unpredictable demand, researchers have also used multivariate models ${ }^{[19]}$. By using various explanatory variables they have attempted to forecast with accuracy future emergency hospital admissions. In that way, health authorities have attempted to form a model to detect variations in the number of hospital admissions. Such policies could ensure optimal management and allocation of hospital health care resources. Baker et al. ${ }^{[8]}$ in the US hospital context discussed the daily variations in hospital utilization and their effects on cost structure. Among the explanatory factors tested by Baker et al. ${ }^{[8]}$ were the weekend and official holiday variables. They found that daily census is higher during the week days and lower on weekends and in the days close to official holidays. They explain these drops in daily census during these specific days of the week or year by the fact that at least some hospital utilization is elective. Therefore these admissions can be scheduled to coincide with convenient times for both patients and medical staff. During the same time period, in Italy, Fusco et al. ${ }^{\left[{ }^{[20]}\right.}$ found similar results. Specifically, bed occupancy decreased over weekends, on national holidays, and during the major holiday season of August. Also, the largest fluctuations were observed for planned/elective stays. Another empirical study by Fullerton and Crawford ${ }^{[21]}$ showed that in the UK, occupancy rates were significantly higher in days where the hospital was 'on duty' and lower at Christmas holidays, compared with the rest of the year. Summer vacation as a seasonal variation of hospital admission due to administration was tested by Upshur et al. ${ }^{[22]}$, in Ontario, Canada. They found that hospital admissions decline during summer in a consistent and predictable pattern. Additionally, researchers have also tested the impact of weekly and seasonal (yearly) effect on specific medical problems. In particular, Peckova et al. ${ }^{[23]}$ have found that cardiac arrests do not occur randomly during the week or year but follow certain periodic patterns. These patterns are probably associated with patterns of activities. They observed that daily variation peaks on Monday and seasonal variation peaks in the winter.

Many researchers have attempted to analyze the reasons why the phenomenon of decreasing admissions during weekend, summer and official holidays is highly present in health care services and particularly, in hospital services. It has been concluded that this might be caused either indirect by the doctors - demand for leisure ${ }^{[24-27]}$, or direct by the hospital itself - organizational structure ${ }^{[28,29]}$. The latter includes the closure of operating theatres at evening and night shifts in weekdays and their totally closing during weekends. The similar schedule follows hospital laboratories and administrative services, apart a few hospital departments related to patients' admissions. However, such an organizational structure might deteriorate the quality of hospital output ${ }^{[30,31]}$. Arias et al. ${ }^{[32]}$ have found that paediatric patients admitted to the Intensive Care Units during evening hours had higher mortality rates than those admitted during daytime's hours. Thus, on one side (supply) hospitals would prefer to postpone any weekend admissions to weekdays when the hospital can fully supply all its services and on the other side (demand) patients would prefer to be admitted on weekdays because they feel more secure for their health progress. Hence, it is hypothesized that the weekend effect, the summer holiday effect and the official holiday effect have a negative impact on hospital admissions.

Public hospitals in the Greek the National Health System (NHS) are required to be on duty and serve emergency admissions on certain days according to a rotation system. This is true in cities where more than one general public hospitals exist in the same geographical area. In such duty days referral hospitals admit only the emergent cases reaching their doors. No elective admissions are admitted on these days. In Piraeus, public hospitals are on duty every third day, during the period under examination, 2001-2005. Being on duty implies that more emergency admissions are accepted. Thus, it is assumed that the duty effect has a positive impact on emergency hospital admissions. 
The purpose of this study is to estimate the unpredictable part of hospital demand in the two greatest public general hospitals in Piraeus, Greece. The daily index of emergency admissions for a five-year time period, from 2001 to 2005 it is used. To estimate the magnitude of unpredictable hospital demand, two approaches are applied: a univariate and a multivariate model. By doing so, it is possible to make comparisons between the two different methods, and to suggest the most easily applicable by hospital managers.

\section{Methods}

\subsection{The Piraeus hospitals}

The Prefecture of Piraeus is located in the west part of Attica, Greece. Its permanent population is amounted to 553,450 people, according to the 2001 census. The health needs of the Piraeus residents are mainly covered by the four public hospitals located in various municipals of Piraeus:

General Hospital of Piraeus "Tzaneio".

General Hospital of Nikaias Piraeus "Aghios Panteleimon".

Anti-Cancer Hospital of Piraeus "Metaxa".

General Hospital-Health Centre of Kithira.

In addition, private health care services exist in the Prefecture of Piraeus, which serve the health care needs of the population but such a discussion here is out of the scope of this paper. The public hospitals in Piraeus are part of NHS in Greece.

We use only the general public hospitals exist in Piraeus, for homogeneity reasons. Thus, only two, Tzaneio and Nikaias hospitals, provide general secondary health care services. We include both hospitals in the sample. They provide both elective and emergency health services. The first one - Tzaneio Hospital - is located in the city of Piraeus, and the second one - Nikaias Hospital - is located in the city of Nikaias. Their capacity varies from 474 beds in Tzaneio hospital to 616 beds in Nikaias hospital, in 2005.

Tzaneio hospital has firstly operated in 1873 and thereafter it has been changed considerably. In 2007, it had 474 developed beds distributed in three different medical sectors: Pathological Sector (nine medical departments and five medical units), Surgical Sector (11 medical departments), and Psychiatric Sector (one medical department). Additionally, the Tzaneio hospital has three multi-sector departments: Day Clinic, Accident and Emergency Department, and Social Services Department, and 11 Laboratories.

Nikaias hospital started during the period of Asia Minor Devastation in 1922, but only after the end of 2nd World War in 1952 it acquired its today's legal entity as one of the public providers of health care services in the Prefecture of Piraeus. Its developed beds, in 2008, were 616, distributed in the three medical sectors: Pathological Sector (12 medical departments and eight medical units), Surgical Sector (14 medical departments and seven medical units), and Psychiatric Sector (two medical departments). In Nikaias hospital also operates the Laboratory Sector, with 12 departments and three units, and two multi-sector departments, these are, Day Clinic and Accident and Emergency Department.

\subsection{Data sources}

The data comes from routine administrative sources that are part of the Hospital Management Information System of the two public general hospitals located in the geographical region of Piraeus, Greece. We collected daily data of emergency admissions from 1st January 2001 to 31st December 2005 (1,826 observations) from the Admissions Department of the two hospitals with the assistance of the information technology department. The sampled hospitals keep separate files for elective and emergency admissions. The disaggregation of admissions into elective and emergency becomes by the 
hospital physicians when the patients come into the hospital. The data on emergency hospital admissions were entered in a Microsoft Office Excel 2007 file and organized by date of admission. Further data management was performed in the same file to process the additional covariates of interest with regards to the weekend, the hospitals' "on duty" days, the summer holidays and the official public holidays.

\subsection{The models}

Two models are applied to estimate the unpredictable demand for hospital care. First, we adopt a univariate autoregressive moving average (ARMA) modelling. This is the most commonly technique for forecasting hospital admissions ${ }^{[12,14,18,33-36]}$ and bed occupancy ${ }^{[14,30]}$ used in the health service literature. In its general form, the mathematical expression of an ARMA model can be represented as follows:

$$
Q_{t}=\sum_{i=1}^{p} \varphi_{i} Q_{i-t}+\sum_{i=1}^{q} \theta_{i} \varepsilon_{i-t}+\varepsilon_{t}
$$

where $\mathrm{Q}_{\mathrm{t}}$ are hospital emergency admissions in day $(\mathrm{t}), \varphi_{1}, \varphi_{2} \ldots \varphi_{\mathrm{p}}$ are the parameters of the autoregressive term of the model, $\theta_{1}, \theta_{2} \ldots \theta_{\mathrm{q}}$ are the parameters of the moving average term and $\varepsilon_{\mathrm{t}}$ is an Independent and Identically Distributed (IID) error term with mean of zero and constant variance. The equation (1) can be considered as having two parts.

In this paper, we use hospital emergency admissions as the dependent variable to estimate unpredictable demand. ARMA is a regression model where the explanatory variables are lags of the dependent variable. According to this model, the unpredictable demand is based on a residual estimate of forecasted daily emergency demand. Thus, the level of unpredictable demand faced by a hospital is defined as the difference between realised and forecasted emergency demand, gained from ARMA forecasting model.

Second, a multivariate time series model is used to estimate unpredictable demand. We test the impact of four explanatory dummy variables on daily emergency hospital admissions. The variables that most commonly have been used are the weekend effect, the hospital "on duty" effect, the summer holiday effect and the official holiday effect, all measuring different impacts. The forecasted residuals from each hospital regression for five years are employed as proxies for unexpected demand. They might be either positive or negative. They are positive when the observed admissions are more than the forecasted and they are negative when the observed admissions are fewer than the forecasted.

To test the impact of the four explanatory variables on emergency hospital admissions we used the method of Ordinary Least Square (OLS). All analyses were conducted using E-views econometric package, version 5.1.

\section{Results}

\subsection{Descriptive statistics}

The absolute number of total admissions in Tzaneio hospital continuously increases over the five-year period (an increase of $33 \%$ from 2001 to 2005). It rose from 24,055 total admissions, in 2001 to 31,978 admissions, in 2005. Diachronically, the analogy of emergency admissions to total admissions is kept almost stable and it amounts to $70 \%$. In absolute numbers, they increased from 16,849 emergency admissions, in 2001 to 22,569 emergency admissions, in 2005 (an increase of 34\%). Similarly, elective admissions rose by 31\% from 2001 to 2005 (from 7,206 to 9,409) (see Figure 1). 
Figure 1. The development of elective and emergency admissions in Tzaneio hospital, 2001-2005

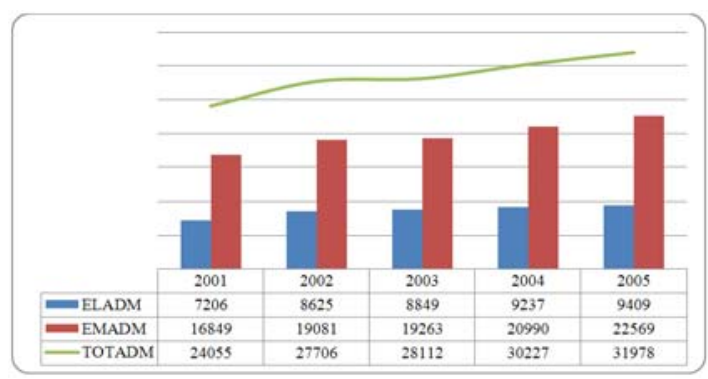

In Nikaias hospital, we notice a different pattern in terms of progress of elective and emergency hospital admissions over the time period under investigation. First, elective admissions increased significantly, almost $80 \%$, between 2001 and 2005. Particularly, they climbed from 1,966 elective admissions, in 2001 to 3,489 elective admissions, in 2005. Second, emergency admissions decreased from 29,978 admissions, in 2001 to 28,191 admissions, in 2005 (a decline of 6\%). As a result, total admissions in Nikaias hospital noticed a small fall by $0.8 \%$. The share of emergency admissions to total admissions varies from 88\%, in 2004 to 94\%, in 2001 (see Figure 2).

Figure 2. The development of elective and emergency admissions in Nikaias hospital, 2001-2005

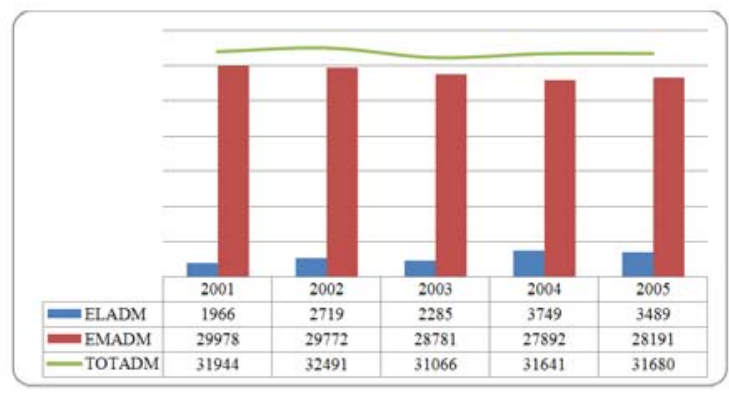

The number of emergency admissions varies considerable over the five year period in Tzaneio and Nikaias hospitals in Piraeus. In Tzaneio hospital, the mean daily emergency admissions, over the five years, are 50 with a standard deviation of 53. In Nikaias hospital, the mean number of emergency hospital admissions equals to 79 with the standard deviation to be equal to 58 admissions (see Table 1).

The annual mean number of emergency admissions in Tzaneio hospital gradually increases, while in Nikaias hospital it decreases, over the five-year period under consideration. The Nikaias hospital accepts approximately $60 \%$ more emergent cases than these accept the Tzaneio hospital, based on the whole-period mean values (see Table 1). The mean standard deviation is larger in Nikaias hospital (58.46) than this in Tzaneio hospital (52.81). Both distributions are skewed to the right. Their median values are smaller that the mean values. This can also be assured from the maximum value in both Tzaneio and Nikaias hospitals. In the former, it is almost four times greater than the mean value, while in latter, it is approximately three times greater than the mean. This ascertainment has significant administrative implications. Hospital managers should be prepared to accept this huge bulk of patients in a day. This means that their hospitals should be standby in terms of hospital beds, staff, drugs and other supplies, with important implications on hospital costs ${ }^{[12,16,18]}$.

Figure 3(a). presents day variations in the Piraeus hospitals. In both hospitals, we could notice a weekend effect on emergency admissions. This effect is considerably stronger in Nikaias hospital than this in Tzaneio hospital. Mean emergency admissions falls by $10 \%$ from the weekday average to the weekend average, in Tzaneio hospital. Contrary, in Nikaias hospital, the mean number of emergency admissions falls by $46 \%$ in weekend compared to the weekday average.

From Figure 3(b), it is apparent that exist month variations. First, both hospitals face less emergency admissions, in average, during July and August (summer effect). This situation is also true for the month of December (Christmas 
holidays) and less obvious for the months of April and May (Easter holidays) - (official holiday's effect). These effects are also tested econometrically, and the results are presented in the next paragraph.

Table 1. The descriptive statistics of Tzaneio and Nikaias hospitals per year, 2001-2005

\begin{tabular}{|c|c|c|c|c|c|c|c|}
\hline $\begin{array}{l}\text { Emergency } \\
\text { Admissions } \\
\text { Dependent } \\
\text { Variable }\end{array}$ & Mean & Std. Dev. & Median & Max & Skewness & Kurtosis & $\begin{array}{l}\text { Jarque-Bere } \\
\text { (Probability) }\end{array}$ \\
\hline \multicolumn{8}{|c|}{ Tzaneio Hospital } \\
\hline $\begin{array}{l}2001 \\
(\mathrm{~N}=365)\end{array}$ & 40 & 52 & 5 & 163 & 0.83 & 1.86 & $\begin{array}{l}61.3898 \\
(0.0000)\end{array}$ \\
\hline $\begin{array}{l}2002 \\
(\mathrm{~N}=365)\end{array}$ & 46 & 48 & 26 & 173 & 0.72 & 2.02 & $\begin{array}{l}45.8824 \\
(0.0000)\end{array}$ \\
\hline $\begin{array}{l}2003 \\
(\mathrm{~N}=365)\end{array}$ & 47 & 46 & 29 & 157 & 0.69 & 1.91 & $\begin{array}{l}46.8039 \\
(0.0000)\end{array}$ \\
\hline $\begin{array}{l}2004 \\
(N=366)\end{array}$ & 57 & 57 & 33 & 185 & 0.72 & 1.91 & $\begin{array}{l}49.9022 \\
(0.0000)\end{array}$ \\
\hline $\begin{array}{l}2005 \\
(\mathrm{~N}=365)\end{array}$ & 62 & 57 & 41 & 195 & 0.64 & 1.86 & $\begin{array}{l}44.5190 \\
(0.0000)\end{array}$ \\
\hline $\begin{array}{l}2001-2005 \\
(\mathrm{~N}=1826)\end{array}$ & 50 & 53 & 28 & 195 & 0.75 & 2.07 & $\begin{array}{l}239.7683 \\
(0.0000)\end{array}$ \\
\hline \multicolumn{8}{|c|}{ Nikaias Hospital } \\
\hline $\begin{array}{l}2001 \\
(N=365)\end{array}$ & 82 & 64 & 60 & 239 & 0.74 & 2.38 & $\begin{array}{l}39.3535 \\
(0.0000)\end{array}$ \\
\hline $\begin{array}{l}2002 \\
(\mathrm{~N}=365)\end{array}$ & 82 & 61 & 63 & 227 & 0.65 & 2.21 & $\begin{array}{l}34.9207 \\
(0.0000)\end{array}$ \\
\hline $\begin{array}{l}2003 \\
(\mathrm{~N}=365)\end{array}$ & 79 & 58 & 64 & 220 & 0.65 & 2.32 & $\begin{array}{l}32.5322 \\
(0.0000)\end{array}$ \\
\hline $\begin{array}{l}2004 \\
(N=366)\end{array}$ & 76 & 55 & 62.5 & 206 & 0.65 & 2.28 & $\begin{array}{l}33.6243 \\
(0.0000)\end{array}$ \\
\hline $\begin{array}{l}2005 \\
(\mathrm{~N}=365)\end{array}$ & 77 & 54 & 68 & 205 & 0.61 & 2.27 & $\begin{array}{l}30.5792 \\
(0.0000)\end{array}$ \\
\hline $\begin{array}{l}2001-2005 \\
(\mathrm{~N}=1826)\end{array}$ & 79 & 58 & 63 & 239 & 0.68 & 2.45 & $\begin{array}{l}172.7416 \\
(0.0000)\end{array}$ \\
\hline
\end{tabular}

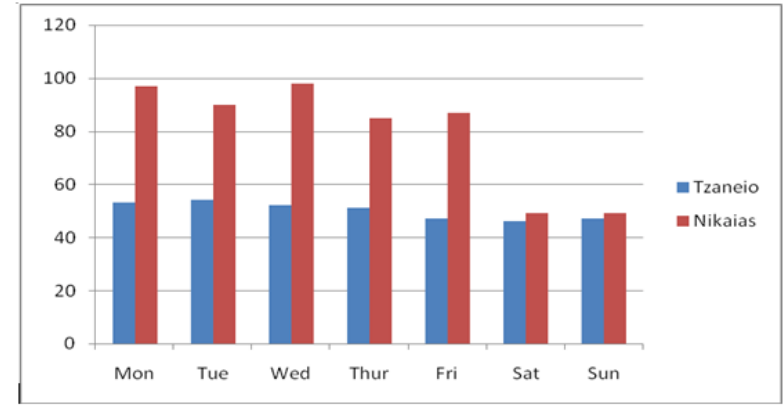

(a) Day variations

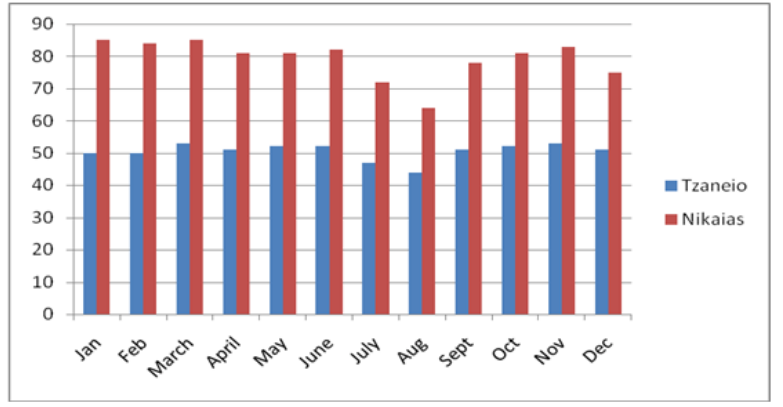

(b) Month variations

Figure 3. Time variations of emergency admissions, 2001-2005 


\subsection{Regression results}

\subsubsection{The univariate estimation of unpredictable hospital demand variations}

In the previous section, it was presented the ARMA approach as one method of measuring unpredictable hospital demand. This section applies this method to emergency hospital admissions data to estimate daily variability measures of unpredictable demand for the two public hospitals of the sample for five years. There are three steps in this approach:

Step 1: Testing the unit root and stationarity of data.

Step 2: Estimating the appropriate ARMA.

Step 3: Decide on the best model based upon statistical criteria.

The first step tests for stationarity of the daily emergency admissions. This implies that the parameters of the distribution of emergency admissions (mean and standard deviation) do not change over time. This is examined by testing for a unit root, i.e. non-stationarity in the time series data. The standard Augmented Dickey-Fuller test (ADF) is commonly used to test for a unit root, and it is given as follows:

$$
\Delta Q_{t}=\alpha_{0}+\beta_{t}+\alpha_{1} Q_{t-1}+\sum \gamma_{j} \Delta Q_{t-j}+\varepsilon_{t} \quad(j=1,2, \cdots, p)
$$

Where $Q_{t}$ is the variable of emergency admissions at time $t, \varepsilon_{t}$ is the error term and $\alpha_{0}, \beta, \alpha_{1}$ and $\gamma_{j}$ are the parameters to be estimated. The lag terms are introduced in order to account that the error terms are uncorrelated with lag terms. For the above-specified model the hypothesis, which would be of interest, is:

$$
H_{0}: \alpha_{0}=0 \text { and } \alpha_{1}=0
$$

The results of the unit root tests for the sampled hospitals reveal that the null hypothesis of unit root is rejected at the $1 \%$ level of significance implying that the series are stationary at the level for both hospitals. The existence of stationarity at the level implies that the emergency hospital admissions series can be modeled without differencing it. In other words, an ARMA specification and not an ARIMA specification can be applied.

The second step is to choose the number of lags from past daily admissions and the number of lags of past errors, to be used in predicting the variable. In practice, it is desirable to find the smallest values of $\varphi$ and $\theta$ (Equation 1) which provide an acceptable fit to the data. With the third step we decide on the best model based upon statistical criteria. The criteria for selecting the best ARMA model specification are those proposed by Akaike and Schwarz (Step 3). The lower the values of the Akaike-Schwartz criterion, the most appropriate the ARMA model. The optimal lag values of the AR and MA process in estimating a univariate model of unpredictable demand for each hospital of the sample equals to 10 past values for Tzaneio hospital and to 11 past values for Nikaias hospital, i.e. $(10,10)$ and $(11,11)$, respectively.

Each hospital's estimation process provides an estimate of the residual $\left(\varepsilon_{t}\right)$, which is the unpredictable part of emergency daily admissions. These residuals have a zero mean and their standard deviation is constant.

To estimate annual variations of unpredictable demand two ways are applied. In the first case, all the residuals forecasts, both positive and negative are used. The forecast errors are positive when actual (emergency admissions) are more than the fitted, while they are negative when the actual are less than the fitted. According to the theory, if we sum up these, the result should be equal to zero. To overcome this, I took the absolute values of the negative forecast errors. In the second case, only the positive values of forecast errors, excluding all the negative ones are used. This is called "excess demand" for unpredictable admissions. 
Table 2(a) reports measures of standard deviation of unpredictable emergency admissions per hospital per year. It includes all residuals, both positive and negative. As can be seen, the unpredictable part of emergency admissions is not the same for the two hospitals and it also varies over the years.

Table 2. Variations in unpredictable daily hospital demand from univariate ARMA model

\begin{tabular}{|c|c|c|c|c|c|c|}
\hline \multicolumn{7}{|c|}{ All ARMA forecast errors $(\mathrm{N}=1826)$ (a) } \\
\hline & Hospital & 2001 & 2002 & 2003 & 2004 & 2005 \\
\hline 1 & Tzaneio & 9.4 & 11.5 & 13.5 & 16.7 & 13.8 \\
\hline 2 & Nikaias & 17.8 & 17.1 & 20.6 & 15.7 & 16.1 \\
\hline \multicolumn{7}{|c|}{ All positive ARMA forecast errors $(\mathrm{N}=1826)$ (b) } \\
\hline & Hospital & 2001 & 2002 & 2003 & 2004 & 2005 \\
\hline 1 & Tzaneio & 7.1 & 9.1 & 9.6 & 10.7 & 10.2 \\
\hline 2 & Nikaias & 10.4 & 10.6 & 12.6 & 9.6 & 9.4 \\
\hline
\end{tabular}

The results reported in Table 2(a) are treated as equally important variations of daily emergency admissions around its mean. However, what is important for the hospital manager are the cases that emergency admissions are greater than forecasted because then they are forced to turn away patients or treat them with lower than expected quality, i.e. put them in beds in the corridors of the hospital. Table 2(b) presents data on the variability of emergency admissions when the actual emergency admissions are above the ones predicted by the model. In other words, it excludes the negative values of the error term. Taking only the positive values of forecast errors gives a lower extent of variations of "excess demand" for hospital admissions. The variations of unpredictable hospital demand have increased by about $45 \%$ in Tzaneio hospital and have decreased by about $10 \%$ in Nikaias hospital.

\subsubsection{The multivariate estimation of unpredictable hospital demand variations}

The multivariate approach develops a regression model with daily emergency admissions as the dependent variable and four explanatory variables - the weekend effect, the summer holiday effect, the official holiday effect, and the duty effect. The first three are expected to have a negative impact and the fourth variable a positive impact on emergency admissions. The regression results per hospital are provided in Table 3. All variables have the expected sign in both hospital regressions. However, they do differ in terms of the quantitative impact as this is demonstrated by the magnitude of the coefficient. Overall daily hospital emergency variations are well explained by the four explanatory variables. The adjusted $\mathrm{R} 2$ is $86 \%$ for both hospitals.

Table 3. Regressions results per hospital, 2001-2005

\begin{tabular}{|c|c|c|c|c|c|c|c|c|}
\hline \multirow{2}{*}{ a/aHospital } & \multicolumn{5}{|c|}{ Explanatory Variables* } & \multirow{2}{*}{ Adj-R2 } & \multirow{2}{*}{$\mathbf{F}$} & \multirow{2}{*}{ S.E.R } \\
\hline & Constant & Weekend & $\begin{array}{l}\text { Summer } \\
\text { Holiday }\end{array}$ & $\begin{array}{l}\text { Official } \\
\text { Holiday }\end{array}$ & Duty & & & \\
\hline 1 Tzaneio & $\begin{array}{l}18.51 \\
(27.84)\end{array}$ & $\begin{array}{l}-4.96 \\
(-4.93)\end{array}$ & $\begin{array}{l}-6.48 \\
(-5.35)\end{array}$ & $\begin{array}{l}-7.31 \\
(-3.19)\end{array}$ & $\begin{array}{l}104 \\
(108.0)\end{array}$ & 86.52 & $\begin{array}{l}2929 \\
(0.0000)\end{array}$ & 19.39 \\
\hline 2 Nikaias & $\begin{array}{l}59.73 \\
(80.34)\end{array}$ & $\begin{array}{l}-42.35 \\
(-37.76)\end{array}$ & $\begin{array}{l}-14.45 \\
(-10.69)\end{array}$ & $\begin{array}{l}-33.78 \\
(-13.21)\end{array}$ & $\begin{array}{l}106 \\
(98.80)\end{array}$ & 86.3 & $\begin{array}{l}2874 \\
(0.0000)\end{array}$ & 21.64 \\
\hline
\end{tabular}

* All estimations are significant at $1 \%$ level. The $t$-statistics are shown in the parentheses.

The standard error of regression (SER) measures the variation in the unpredicted part of the daily emergency admissions. The error series of the multivariate model are used to estimate variations in unexpected demand per hospital and per year. It is exactly the same procedure followed in the univariate model, which was presented above. The results are given in Table 4. 
Table 4. Variations in unpredictable daily hospital demand from multivariate model

\begin{tabular}{|c|c|c|c|c|c|c|}
\hline \multicolumn{7}{|c|}{ All Multivariate forecast errors ( $\mathrm{N}=1826)(\mathrm{a})$} \\
\hline & Hospital & 2001 & 2002 & 2003 & 2004 & 2005 \\
\hline 1 & Tzaneio & 10.2 & 16.9 & 18.0 & 20.9 & 20.0 \\
\hline 2 & Nikaias & 22.4 & 21.3 & 22.2 & 20.8 & 20.9 \\
\hline \multicolumn{7}{|c|}{ All Positive Multivariate forecast errors $(\mathrm{N}=1826)(\mathrm{b})$} \\
\hline & Hospital & 2001 & 2002 & 2003 & 2004 & 2005 \\
\hline 1 & Tzaneio & 8.8 & 10.5 & 10.1 & 13.0 & 14.0 \\
\hline 2 & Nikaias & 15.3 & 12.8 & 12.2 & 11.0 & 11.9 \\
\hline
\end{tabular}

The results of Table 4(b) shows that the variations in unpredictable daily demand in Tzaneio hospitals have less than doubled over the five-year period under investigation. They have increased from nine admissions in 2001 to 14 admissions in 2005. Contrary to this, the variations in unpredictable daily demand in Nikaias hospital have decreased by $20 \%$ from 2001 to 2005. They have reduced from 15 admissions to 12 admissions. Due to these trends, a general conclusion is that at the beginning of the time period under investigation there are large variations in unpredictable demand between the two hospitals, which become smaller as we move on to 2005. Similar trends are noticed when we look at Table 4(a), where all multivariate forecast errors (both positive and negative) are used.

\section{Conclusions and discussion}

This paper uses two methods to measure unpredictable hospital demand in two public NHS hospitals in Piraeus, Greece, during the period 2001-2005: first, a univariate Autoregressive Moving Average model and second a multivariate time series model. In the latter one, four explanatory variables are tested: the weekend effect, the duty effect, the summer holiday effect, and the official holiday effect.

To my knowledge this issue has not been investigated in Greece. Emergency hospital admissions decline during summer months, weekends, and official holidays but increase during "on duty" days. These findings are similar with those found in other studies conducted in different health care systems ${ }^{[21,22,34]}$.

From the descriptive statistics results that emergency admissions as a percentage of total admissions accounts for $70 \%$, in Tzaneio hospital and approximately to $90 \%$, in Nikaias hospital. In Tzaneio hospital, emergency admissions have increased by about $30 \%$ over the five-year period. Contrary, in Nikaias hospital, emergency admissions have declined by about 6\% from 2001 to 2005. In Tzaneio hospital, the mean daily emergency admissions are 50 with a standard deviation of 53, while in Nikaias hospital, the mean number of emergency hospital admissions equals to 79 with the standard deviation to be equal to 58 admissions. These results could be explained due to the very good publicity that the Tzaneio hospital has all over the country. For instance, many people from other surrounding cities arrange to do their medical exams and surgeries in the Tzaneio hospital, in Piraeus (see Statistics, in www.tzaneio.gr). On the other hand, the Nikaias hospital faces considerable competition from the Attikon hospital that covers the wider area of west part of Attica, including the city of Nikaia. The absolute number elective surgeries have been decreased over time (see statistics, in www.nikaias-hosp.gr).

As far as the day and month variations in the Piraeus hospitals are concerned, they exist in both hospitals. In Nikaias hospital, the three out of four variables (weekend effect, summer effect and official holiday effect) have stronger effects than these in Tzaneio in the variability of emergency hospital admissions. This result could be explained from the fact that the Tzaneio hospital is located in the city centre of Piraeus, where the permanent population, according to the recent registry (2011), is 55\% larger than this in Nikaia city (see, Press Release, 28/12/2012, ELSTAT, www.statistics.gr). Also, this could happen due to the fact that the city of Piraeus has the biggest port in Greece and it is one of the biggest business centre with many big shipping companies located in the city centre. This highly productivity creates increased demand for 
visiting to doctors and hospitalization independently of the day and time period of admission. Opposite, the city of Nikaias, a neighbouring city is a considerably smaller business centre than this of Piraeus city. The duty effect has a similarly positive impact on hospital emergency admissions in both public hospitals.

Independently of the model we apply, in Tzaneio hospital, the unexpected part of emergency admissions increases over the five-year period, while in Nikaias hospital, it reduces. From the univariate analysis, it was found that the unpredictable part of admissions is not the same for the two hospitals and it also varies over the years. When it is used only the positive values of forecast errors it gives a lower extent of variations of excess demand for hospital admissions, compared to the case that all, positive and negative forecast errors are applied. Over the five-year period, the variations of unpredictable hospital demand have increased by about $45 \%$ in Tzaneio hospital and have decreased by about $10 \%$ in Nikaias hospital. The results from the multivariate analysis shows that the variations in unpredictable daily demand in Tzaneio hospitals have less than doubled over the five-year period under investigation. They have increased from nine admissions in 2001 to 14 admissions in 2005. Contrary, the variations in unpredictable daily demand in Nikaias hospital have decreased by $20 \%$ from 2001 to 2005. They have reduced from 15 admissions to 12 admissions. In absolute numbers, these findings are in parallel with those found earlier in terms of the two hospitals' productivity - in Tzaneio hospital it is noticed a continuously increase of outcomes, while in Nikaias hospital the trend of its productivity is decreasing, over time.

A general conclusion is that at the beginning of the time period under investigation there are large variations in unpredictable demand between the two hospitals, which become smaller as we move on to 2005. As we mentioned earlier, the operation of the Attikon hospital at the beginning of 2000, in the west part of Greece attracted a great number of people, not only from the surrounding area but from the whole Greece. Many patients felt more secure to admit in this newly established hospital, where there were new machines, new technologies and new infrastructures. However, the investigation of these trends in unpredictable hospital demand variations over the time period examined is out of the scope of this paper and it is a topic for further and future research interest.

The accurate forecasting of future demand assists hospitals in programming short-term needs such as staff and supplies, and long-term needs such as beds and buildings. The existence of the appropriate methodological instruments, applied by hospital managers, could help them smooth down upcoming patient flows and beds, and assist health policy makers to plan a priori, in an efficient way, the allocation of scarce hospital resources ${ }^{[14,21,22,34,37]}$.

For the present study, we notice two drawbacks.

First, in the literature more extended models have been used to forecast hospital demand. For example, epidemiological data ${ }^{[34]}$ and weather and pollution information are the most commonly used ${ }^{[14,19,36]}$. The use of extensive and detailed pollution and weather data could shed some light in the variations of hospital emergency admissions in the Greek NHS and provide us with more accurate future projections of number of patients arrived at hospitals.

Second, this study does not connect the variations of unexpected demand and hospital costs. If unexpected demand raises hospital costs, as it is the case in other country settings, then the multivariate model can give some guidance to hospital administrators of how to reduce the variability of emergency admissions. Previous empirical studies in Greece have found that public hospitals are inefficient ${ }^{[38,39]}$. Further research should include stochastic demand as one of the explanatory variables into the hospital costs functions in order to investigate whether part of this inefficiency could be explained by the reserve capacity held by hospitals due to uncertain demand.

\section{Acknowledgements}

I would like to thank the Greek National Scholarship Foundation (IKY) for its financial support to my postgraduate studies. Also, I thank very much Professor Ann Netten, University of KENT, Professor Alistair Gray, University of Oxford, and an anonymous referee for their guidance and their support. 


\section{References}

[1] Acton, J.P. Nonmonetary factors in the demand for medical services: some empirical evidence. The Journal of Political Economy. 1975; 83(3): 595-614. http://dx.doi.org/10.1086/260342

[2] Noble, J.H., M.E. LaMontagne, C. Bellotti, H. Wechsler. Variations in visits to hospital emergency care facilities: ritualistic and meteorological factors affecting supply and demand. Medical Care. 1971; 9(5): 415-427. PMid: 5123759. http://dx.doi.org/10.1097/00005650-197109000-00005

[3] Levy, M., H. Kewitz, W. Altwein, J. Hillebrand, M. Eliakim. Hospital admissions due to adverse drug reactions: a comparative study from Jerusalem and Berlin. European Journal of Clinical Pharmacology. 1980; 17: 25-31. PMid: 7371696 http://dx.doi.org/10.1007/BF00561673

[4] Rohrer, J.E. Supply-induced demand for hospital care. Health Services Management Research. 1980; 3(1): 41-48.

[5] Kroneman, M., J.J. Siegers. The effect of hospital bed reduction on the use of beds: a comparative study of 10 European countries. Social Science and Medicine. 2004; 59(8): 1731-1740. PMid: 15279929. http://dx.doi.org/10.1016/j.socscimed.2004.01.036

[6] Van Uden, C.J., H.F. Crebolder. Does setting up out of hours primary care cooperatives outside a hospital reduce demand for emergency care? Emergency Medicine Journal. 2004; 21(6): 722-723. PMid: 15496709. http://dx.doi.org/10.1136/emj.2004.016071

[7] Boutsioli, Z. Hospital costs and unexpected demand: the case of Greece. The Open Economics Journal. 2011a; 4: 49-58. http://dx.doi.org/10.2174/1874919401104010049

[8] Baker, L.C., C.S. Phibbs, C. Guarino, D. Supina, J.L. Reynolds. Within-year variation in hospital utilization and its implications for hospital costs. Journal of Health Economics. 2004; 23: 191-211. http://dx.doi.org/10.1016/j.jhealeco.2003.09.005

[9] Friedman, B., M.V. Pauly. Cost functions for a service firm with variable quality and stochastic demand: The case of hospitals. Review of Economics and Statistics. 1983; 63: 620-24. http://dx.doi.org/10.2307/1935859

[10] Friedman, B., M.V. Pauly. A new approach to hospital cost functions and some issues in revenue regulation. Health Care Financing Review. 1981; 4(3): 105-14.

[11] Gaynor, M., G. Anderson. Uncertain demand, the structure of hospital costs and the cost of an empty bed. Journal of Health Economics. 1995; 14: 291-317. http://dx.doi.org/10.1016/0167-6296(95)00004-2

[12] Hughes, D., A. McGuire. Stochastic demand, production responses and hospital costs. Journal of Health Economics. 2003; 22(6), 999-1010. http://dx.doi.org/10.1016/S0167-6296(03)00048-1

[13] Jones, S.S., R.S. Evans, T.L. Allen, A. Thomas, P.J. Haug, S.J. Welch, et al. A multivariate time series approach to modelling and forecasting demand in the emergency department. Journal of Biomedical Informatics. 2009; 41(1): 123-39. PMid: 18571990. http://dx.doi.org/10.1016/j.jbi.2008.05.003

[14] Jones, S.A., M.P. Joy, J. Pearson. Forecasting demand of emergency care. Health Care Management Science.2002; 5:297-305. PMid: 12437279. http://dx.doi.org/10.1023/A:1020390425029

[15] Knox Lovell, C.A., A. Rodriguez-Alvarez, A. Wall. The effects of stochastic demand and expense preference behaviour on public hospital costs and excess capacity. Health Economics. 2008; 18(2): 227-235. PMid: 18435427. http://dx.doi.org/10.1002/hec.1352

[16] Smet, M. Measuring performance in the presence of stochastic demand for hospital services: an analysis of Belgian general care hospitals. Journal of Productivity Annals. 2007; 27: 13-29. http://dx.doi.org/10.1007/s11123-006-0021-7

[17] Almeida, A., J. Cima. Demand uncertainty and hospital costs: an application to Portuguese NHS hospitals. FEP Working Papaer, University of Porto, n. 499. July 2013

[18] Boutsioli, Z. Measuring unexpected hospital demand: the application of a univariate model to public hopsitals in Greece. Hospital Topics. 2009; 87(4, Fall): 14-21.

[19] Diaz, J., J.C. Alberdi, M.S. Pajares, C. Lopez, R. Lopez, M.B. Lage, et al. A model for forecasting emergency hospital admissions: effect of environmental variables. Journal of Environmental Health. 2001; 64(3): 9-15. PMid: 11605333.

[20] Fusco, D., C. Saitto, M. Arca, C. Ancona, C.A. Perucci. Cyclic fluctuations in hospital bed occupancy in Roma (Italy): supply and demand driven? Health Services Management Research. 2003; 16(4): 268-275. PMid: 14613624. http://dx.doi.org/10.1258/095148403322488964

[21] Fullerton, K.J., V.L.S. Crawford. The winter bed crisis - quantifying seasonal effects on hospital bed usage. Quarterly Journal of Medicine. 1999; 92(4): 199-206. http://dx.doi.org/10.1093/qjmed/92.4.199

[22] Upshur, R.E.G., R. Moineddin, E. Crighton, L. Kiefer, M. Mandani. Simplicity within complexity: seasonality and predictability of hospital admissions in the province of Ontario 1988-2001 - a population-based analysis. Health Services Research. 2005; 5(13).

[23] Peckova, M., C.E. Fahrenbruch, L.A. Cobb, A.P. Hallstrom. Weekly and seasonal variations in the incidence of cardiac arrests. American Heart Journal. 1999; 137(3): 512-515. http://dx.doi.org/10.1016/S0002-8703(99)70507-7 
[24] Brown, H.S. Physician demand for leisure: implications for caesarean section rates. Journal of Health Economics. 1996; 15(2): 233-242. http://dx.doi.org/10.1016/0167-6296(95)00039-9

[25] Font, J.C. Do incentives, complexity and the demand for leisure explain caesarean-sections deliveries? International Journal of Social Economics. 2009; 36(9): 906-915. http://dx.doi.org/10.1108/03068290910977739

[26] Mossialos, E., S. Allin, K. Karras, K. Davaki. An investigation of Caesarean sections in three Greek hospitals. European Journal of Public Health. 2005a; 15(3): 288-95. PMid: 15923214. http://dx.doi.org/10.1093/eurpub/cki002

[27] Mossialos, E., J. Costa-Fonta, K. Davaki, K. Karras. Is there 'patient selection' in the demand for private maternity care in Greece? Applied Economic Letters. 2005a; 12: 7-12. http://dx.doi.org/10.1080/13504850420007099

[28] Fatovich, D.M., R.L. Hirsch. Entry overload, emergency department overcrowding, and ambulance bypass. Emergency Medical Journal. 2003; 20: 406-409. http://dx.doi.org/10.1136/emj.20.5.406

[29] Ryan, M. The phenomenon of the corridor patient. British Medical Journal. 1980; 281: 1483-1484. http://dx.doi.org/10.1136/bmj.281.6253.1483

[30] Earnest, A., I.C.M. Chen, E. Seow. Exploring if day and time of admission is associated with average length of stay among inpatients from a tertiary hospital in Singapore: an analytic study based on routine admission data. BMC Health Services Research. $2005 ; 6(6)$.

[31] Lee, L.H., S.J. Swensen, C.A. Gorman, R.R. Moore, D.L. Wood. Optimizing weekend availability for sophisticated tests and procedures in a large hospital. American Journal of Managed Care. 2005; 11(9): 553-8. PMid: 16159045.

[32] Arias, Y., D.S. Taylor, J.P. Marcin. Association between evening admissions and higher mortality rates in the paediatric Intensive Care Unit. Pediatrics. 2004; 113: 530-534. http://dx.doi.org/10.1542/peds.113.6.e530

[33] Abdel-Aal, R.E., A.M. Mangoud. Modeling and forecasting monthly patient volume at a primary health care clinic using univariate time series analysis. Computer Methods and Programs in Biomedicine. 1998; 56: 235-47. http://dx.doi.org/10.1016/S0169-2607(98)00032-7

[34] Hussain, S., R. Harrison, J. Ayres, S. Walter, J. Hawker, R. Wilson, et al. Estimation and forecasting hospital admissions due to influenza: planning for winter pressures. The case of the West Midlands, UK. Journal of Applied Statistics. 2005; 32(3): 191-205. http://dx.doi.org/10.1080/02664760500054384

[35] Hisnanick, J.J. Forecasting the demand for inpatient services for specific chronic conditions. Journal of Medical Systems. 1994; 18: 9-21. PMid: 8064208. http://dx.doi.org/10.1007/BF00999320

[36] Linares, C., J. Diaz. Impact of high temperatures on hospital admissions: comparative analysis with previous studies about mortality (Madrid). European Journal of Public Health. 2008; 18(3): 317-22. PMid: 18045814.

http://dx.doi.org/10.1093/eurpub/ckm108

[37] Boutsioli, Z. Hospital demand variations: suggested instruments for hospital managers. World Hospitals and Health Services. 2011b; 47(1): 4-7. PMid: 21675630.

[38] Athanassopoulos, A.D., C. Gounaris, A. Sissouras. A descriptive assessment of the production and cost efficiency of general hospitals in Greece. Health Care Management Sciences. 1999; 2: 97-106. http://dx.doi.org/10.1023/A:1019023408924

[39] Giokas, D.I. Greek hospitals: how well their resources are used. Omega - International Journal of Management Science. 2001; 29: 73-83. http://dx.doi.org/10.1016/S0305-0483(00)00031-1 